\title{
A Difference Between Bedtime and Pre-Breakfast Plasma Glucose Levels Indicates the Need for Prandial Insulin in Basal Insulin-Treated Type 2 Diabetic Patients with Normal Fasting Glucose
}

This article was published in the following Dove Press journal:

Diabetes, Metabolic Syndrome and Obesity: Targets and Therapy

\author{
Stephan Kress \\ Anja Borck ${ }^{2}$ \\ Ariel Zisman ${ }^{3}$ \\ Peter Bramlage $e^{4,5}$ \\ Thorsten Siegmund ${ }^{6}$ \\ 'Diabeteszentrum, Vinzentius- \\ Krankenhaus, Landau, Germany; ${ }^{2}$ Medical \\ Department, Sanofi, Berlin, Germany; \\ ${ }^{3}$ The Endocrine Center of Aventura, \\ Aventura, FL, USA; ${ }^{4}$ Institute for \\ Pharmacology and Preventive Medicine, \\ Cloppenburg, Germany; ${ }^{5}$ Department for \\ Angiology, Brandenburg Medical School, \\ Campus Brandenburg/Havel, \\ Brandenburg, Germany; ${ }^{6}$ Diabetes- \\ Hormon- Und Stoffwechselzentrum Am \\ Isar Klinikum München, München, \\ Germany
}

\begin{abstract}
Aim: In the present analysis, we characterised the efficacy and safety of adding a single daily injection of insulin glulisine to optimised basal-supported oral therapy (BOT) in patients with a high BeAM value, defined as a more than $50 \mathrm{mg} / \mathrm{dl}$ difference between bedtime and pre-breakfast blood glucose.

Methods: The BeAM value was retrospectively calculated for patients pooled from two clinical trials that supplemented BOT with glulisine. Data regarding changes in HbAlc, fasting plasma glucose (FPG), and postprandial glucose (PPG) levels from observation periods of 3 to 6 months were assessed.

Results: Out of 358 patients that received BOT/glulisine, 182 had a high BeAM value. Patients with a high BeAM value were older and had a longer diabetes duration than patients with a medium BeAM value. Significant reductions in $\mathrm{HbA1c}(7.5 \%$ to $7.2 \%$ [59 to $55 \mathrm{mmol} / \mathrm{mol}$, $\mathrm{p}<0.0001)$ and PPG (202 to $143 \mathrm{mg} / \mathrm{dl}, \mathrm{p}<0.0001)$ levels were documented. The proportion of patients with a high BeAM value achieving an $\mathrm{HbAlc}<7 \%$ [53 $\mathrm{mmol} / \mathrm{mol}]$, alone or in combination with no hypoglycaemia, was lower than that of patients with a medium BeAM value. Conclusion: The analysis indicates that the supplementation of BOT with a single daily injection of prandial insulin is safe and effective for reducing HbA1c and PPG levels in patients with a high BeAM value (more than $50 \mathrm{mg} / \mathrm{dl}$ ). However, patients with a medium BeAM value also responded well, which suggests that they should also be considered candidates for this change in therapy.
\end{abstract}

Keywords: basal-plus, prandial insulin, type-2 diabetes, glulisine, glargine

\section{Introduction}

Type- 2 diabetes is a progressive disease, with $\beta$-cell function and insulin sensitivity decreasing over time. ${ }^{1}$ As a result, anti-diabetic treatment needs to be gradually intensified in order to maintain glycaemic control. ${ }^{2}$ Oral monotherapy with metformin is usually the first line of treatment after diagnosis followed by oral combination therapy. Eventually, insulin will be necessary if sufficiently low blood glucose levels are to be achieved and maintained. ${ }^{3}$ The addition of long-acting insulin glargine to the oral treatment is a well-established method of intensifying diabetes treatment (basal-supported oral therapy; BOT).

While this approach has been shown to effectively reduce blood glucose levels, postprandial hyperglycaemia can still be a problem in some patients, even those
Correspondence: Stephan Kress

Diabeteszentrum, Vinzentius

Krankenhaus, Cornichonstr. 4, Landau,

76829, Germany

Tel +49634I 172208

Email kress.innere@vinzentius.de
Diabetes, Metabolic Syndrome and Obesity: Targets and Therapy 2021:14 1215-1222 
who have achieved significant reductions in $\mathrm{HbAlc}$ levels. ${ }^{4-6}$ It is essential that such excursions are controlled, as they are associated with increased cardiovascular risk. ${ }^{7-9}$ One approach to overcoming this problem is the use of an injection of a short-acting insulin such as glulisine just prior to the meal with the highest glycaemic impact (basal-plus strategy). ${ }^{10,11}$ This has been shown to effectively improve glycaemic control. ${ }^{12-15}$ However, it is not always clear at what point continued titration of basal insulin stops being beneficial, and prandial insulin supplementation becomes necessary. Therefore, a simple evidence-based method to determine the requirement for prandial insulin supplementation is required.

A straightforward method that provides such criteria has been developed recently. ${ }^{16,17}$ The BeAM value is a factor that is calculated by subtracting a patient's morning (AM) blood glucose level from the one measured at bedtime $(\mathrm{Be})$ the previous night. BeAM was analysed and explored in 1401 patients with type 2 diabetes mellitus; the BeAM categories $<0,0$ to 50 and $>50 \mathrm{mg} / \mathrm{dl}$ corresponded to almost equal proportion of the patients $(33.1 \%, 36.8 \%$ and $30.0 \%$, respectively). ${ }^{16} \mathrm{~A}$ high BeAM value ( $>50 \mathrm{mg} /$ $\mathrm{dl})$ is indicative of postprandial glucose (PPG) excursions during the day giving a large bedtime value, in addition to well-controlled fasting blood glucose (FBG) giving a low morning measurement. Therefore, a high BeAM value suggests the need for prandial insulin supplementation.

In the present study, we retrospectively assessed a population of type 2 diabetes patients with a high BeAM value who were being BOT treated, and evaluated the efficacy and safety of adding a single daily injection of prandial insulin to their treatment regimen.

\section{Materials and Methods Study Design and Patients}

The present study is a retrospective analysis of anonymized data collected in two randomised, multi-centre clinical trials, the Orals Plus Apidra and Lantus (OPAL) study and the Proof-of-Concept (POC) study. ${ }^{13,14}$ Data on the value of a negative BeAM value have been published previously. ${ }^{16}$ The study required no ethical approval as it was based on already collected, anonymized data.

In short, data from a total of 358 patients with type- 2 diabetes who were being treated with insulin glargine, with the subsequent addition of a single pre-meal injection of insulin glulisine at baseline, were included. The BeAM value was calculated for each patient (bedtime blood glucose minus pre-breakfast blood glucose), and patients with a high BeAM value $(>50 \mathrm{mg} / \mathrm{dl})$ were compared to those with a BeAM value between 0 and $50 \mathrm{mg} / \mathrm{dl}$.

Inclusion and exclusion criteria for the two trials are detailed elsewhere. ${ }^{13,14}$ Briefly, in the POC trial, the dose of insulin glargine was optimised via titration against FBG over a period of 3 months to achieve a target value of $\leq 100 \mathrm{mg} / \mathrm{dl}$ at baseline. Insulin glulisine was added prior to the main meal (10 breakfast, 14 lunch, 25 dinner). ${ }^{13}$ In the OPAL trial, 162 patients received their insulin glulisine at breakfast (Group 1), and 154 at the main meal (Group 2; no additional information on which meal was considered to be the "main meal" was provided). ${ }^{14}$ During the screening period, the main mealtime was individually determined by recording the median of mealtime-specific 2-h postprandial (2h-pp) BG values after breakfast (between 06:00 and 09:00 hours), lunch (between 11:00 and 14:00 hours) and dinner (between 18:00 and 21:00 hours) on three different days. The main mealtime was defined as the maximum of the three medians. While there was no specific optimisation, patients were excluded if they recorded more than two FBG readings of $>120 \mathrm{mg} /$ $\mathrm{dl}$ in the five consecutive days before baseline. The purpose of the POC and OPAL trials was to intensify treatment using insulin glulisine were to improve glucose control with respect to the 2h-pp BG values (OPAL: $\leq 7.5$ $\mathrm{mmol} / \mathrm{l}$ ), the FBG (POC and OPAL: $\leq 5.5 \mathrm{mmol} / \mathrm{l}$.

For the BeAM analysis specifically, patients were required to have $\mathrm{HbAlc}$ measurements at the start and end of the trial in order to be included. Any patients with an $\mathrm{HbA} 1 \mathrm{c}$ value $\leq 7 \%$ [53 $\mathrm{mmol} / \mathrm{mol}]$ after insulin glargine optimisation were excluded. During the trial periods, insulin glulisine was titrated to give a 2-h PPG level of $\leq 135 \mathrm{mg} / \mathrm{dl}$ or a pre-meal blood glucose level of $100-120 \mathrm{mg} / \mathrm{dl}$ (POC trial only).

\section{Documentation}

Baseline patient characteristics including age, gender, weight, body mass index (BMI), diabetes history, diabetes treatment history, HbA1c level, FBG level, PPG level, and dosage of both insulin glargine and insulin glulisine were pooled for analysis. A mean 7-point daytime blood glucose profile (before and $2 \mathrm{~h}$ after each meal) was constructed by combining those recorded just prior to the baseline of the two trials. Patient characteristics recorded at the end of the study periods were compared to those recorded at baseline. 
Any hypoglycaemic events that occurred during the trial periods were classified as symptomatic, severe, or nocturnal. Symptomatic hypoglycaemia was defined as blood glucose $<60 \mathrm{mg} / \mathrm{dl}$ with symptoms, while severe hypoglycaemia was defined as blood glucose $<36 \mathrm{mg} / \mathrm{dl}$. These definitions were chosen based on the research protocols of the two underlying trials rather than on more recent recommendations.

\section{Study Endpoints}

The primary objectives of the analysis were to determine the efficacy and safety of adding prandial insulin to BOT in patients with a high BeAM value. This included evaluation of changes in $\mathrm{HbAlc}$, PPG, FPG, weight, and BMI, in addition to the occurrence of hypoglycaemia, after the addition of insulin glulisine. Further composite endpoints were also assessed, defined as 1) HbA1c $<7 \%$ [53 mmol/ mol], 2) $\mathrm{HbAlc}<7 \%$ [53 mmol/mol] and no symptomatic hypoglycaemia, 3) HbAlc $<7 \%$ [53 mmol $/ \mathrm{mol}]$ and no severe hypoglycaemia, 4) $\mathrm{HbA} 1 \mathrm{c}<7 \%[53 \mathrm{mmol} / \mathrm{mol}]$ and no weight gain, 5) $\mathrm{HbA} 1 \mathrm{c}<7 \%$ [53 $\mathrm{mmol} / \mathrm{mol}]$ and no symptomatic hypoglycaemia and no weight gain, 6) $\mathrm{HbA} 1 \mathrm{c}<7 \%$ [53 mmol $/ \mathrm{mol}]$ and no severe hypoglycaemia and no weight gain.

\section{Statistical Analysis}

Descriptive statistics were used to describe patient demographics and clinical characteristics. The count and associated percentage of the total were reported for all categorical variables. The mean and standard deviation (SD) are reported for continuous variables. Descriptive statistics were also used to measure and describe the efficacy and safety outcome measurements. Association of BeAM value with the incidence of hypoglycaemia and composite endpoints were evaluated using logistic regression analyses. Odds ratio (OR) estimates, Wald 95\% confidence intervals, and p-values derived from maximum likelihood estimates are reported. All statistical analyses were carried out using the $\mathrm{SAS}^{\circledR} 9.3$ software.

\section{Results}

\section{Patient Characteristics}

Of the 358 patients included in the analysis, 182 had a high BeAM value $(>50 \mathrm{mg} / \mathrm{dl})$ and 145 were calculated to have a medium BeAM value $(0-50 \mathrm{mg} / \mathrm{dl})$. The high BeAM value group was slightly older (63.9 vs 61.9 years), had a lower mean BMI (30.7 vs $\left.32.3 \mathrm{~kg} / \mathrm{m}^{2}\right)$ and a longer
Table I Patient Characteristics at Baseline

\begin{tabular}{|l|c|c|c|}
\hline & $\begin{array}{c}\text { High BeAM } \\
\text { Value }(\mathbf{n}=\mathbf{1 8 2})\end{array}$ & $\begin{array}{c}\text { Medium BeAM } \\
\text { Value }(\mathbf{n}=145)\end{array}$ & p-value \\
\hline Age (years) & $63.9 \pm 9.0$ & $61.9 \pm 8.7$ & 0.021 \\
\hline Male (\%) & 55.5 & 55.2 & 0.478 \\
\hline Weight (kg) & $87.7 \pm 17.0$ & $92.8 \pm 16.9$ & 0.004 \\
\hline BMI (kg/m²) & $30.7 \pm 5.1$ & $32.3 \pm 5.2$ & 0.003 \\
\hline $\begin{array}{l}\text { HbAlc level (\%) } \\
\text { [mmol/mol] }\end{array}$ & $7.5 \pm 0.7[59 \pm 7]$ & $7.3 \pm 0.7[56 \pm 8]$ & 0.005 \\
\hline FBG (mg/dl) & $105.6 \pm 16.0$ & $108.3 \pm 15.2$ & 0.060 \\
\hline PPG (mg/dl) & $201.8 \pm 47.9$ & $172.9 \pm 33.2$ & $<0.001$ \\
\hline $\begin{array}{l}\text { Diabetes duration } \\
\text { (years) }\end{array}$ & $11.5 \pm 7.4$ & $9.8 \pm 6.5$ & 0.014 \\
\hline $\begin{array}{l}\text { OAD treatment } \\
\text { duration (years) }\end{array}$ & $9.7 \pm 6.7$ & $7.7 \pm 5.3$ & 0.001 \\
\hline $\begin{array}{l}\text { Insulin treatment } \\
\text { duration (years) }\end{array}$ & $2.3 \pm 2.3$ & $1.9 \pm 1.9$ & 0.043 \\
\hline
\end{tabular}

Notes: Data are given as mean $\pm \mathrm{SD}$ or percentage. High BeAM value is $>50 \mathrm{mg} / \mathrm{dl}$; medium BeAM value is $0-50 \mathrm{mg} / \mathrm{dl}$. BMl, body mass index; HbAlc, glycated haemoglobin; FBG, fasting blood glucose; PPG, postprandial glucose; OAD, oral antidiabetic drug.

diabetes duration (11.5 vs 9.8 years) than patients with a medium BeAM (Table 1). Accordingly, the high BeAM group had been treated with both oral antidiabetic drugs and insulin for a longer duration than the medium group. In terms of blood glucose levels, the high BeAM group had a slightly lower mean FBG level (105.6 vs $108.3 \mathrm{mg} /$ dl), slightly higher mean HbAlc (7.5 vs 7.3\% [59 vs 57 $\mathrm{mmol} / \mathrm{mol}])$, and a significantly higher mean PPG (201.8 vs $172.9 \mathrm{mg} / \mathrm{dl}$ ).

Mean 7-point blood glucose profiles constructed from those measured just prior to the baseline of the two trials are shown in Figure 1. It is evident that the high BeAM value group experienced a steeper rise in blood glucose after each of the three meals of the day. This resulted in a significantly higher reading at bedtime (199.9 vs $138.3 \mathrm{mg} / \mathrm{dl}$ for the high and medium groups, respectively).

\section{Changes in Patient Characteristics During the Study Period}

A significant decrease in $\mathrm{HbAlc}$ was documented for the patients in both groups $(\mathrm{p}<0.0001)$ (Table 2). PPG levels also decreased, with a more substantial reduction evident for the high BeAM group. FBG levels increased in both sets of patients $(p<0.0001$ and $p=0.0031$, respectively). 


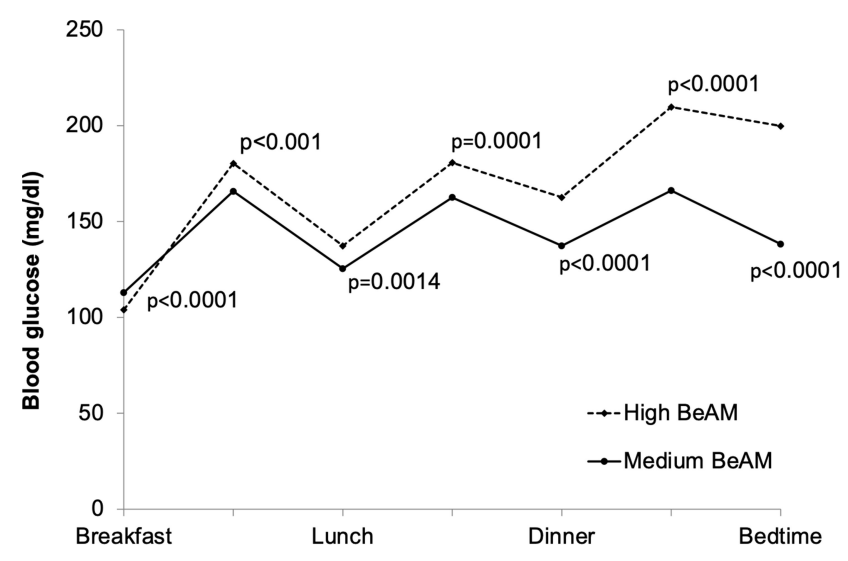

Figure I Variation in daytime blood glucose level at baseline.

Note: Blood glucose measurements were taken before and $2 \mathrm{~h}$ after each meal.

The dosage of insulin glargine increased during the study period for both the high (37.8 to 44.7 units; $\mathrm{p}<0.0001 ; \Delta+6.9$ units) and the medium (35.7 to 42.2 units; $\mathrm{p}<0.0001 ; \Delta+6.5$ units) BeAM value groups. Titration of insulin glulisine during the study resulted in a mean increase in the high group from 5.1 to 12.3 units $(\Delta$ +7.3 units) and in the medium group from 4.9 to 11.2 units $(\Delta+6.3$ units). The high BeAM value group experienced an increase in BMI during the study period, while that of the medium group remained relatively constant.

\section{Endpoint Achievement}

Incidence rates of confirmed symptomatic, nocturnal, and confirmed severe hypoglycaemia were slightly higher for patients with a high BeAM value in comparison to those with a medium value (Table 3 ). The proportion of patients achieving an HbAlc level below the target of 7\% [53 $\mathrm{mmol} / \mathrm{mol}]$, on the other hand, was lower for the high
BeAM group in comparison to the medium group (39.0 vs $62.8 \%$, respectively; Table 3 ). This trend was also evident for each of the composite endpoints, although for those including no weight gain, this was less distinct. Accordingly, a high BeAM value was found to be a predictor for a lower achievement rate for the composite endpoints of $\mathrm{HbAlc}<7 \%$ [53 $\mathrm{mmol} / \mathrm{mol}]$, and $\mathrm{HbAlc}$ $<7 \%$ [53 mmol/mol] plus no incidence of confirmed symptomatic hypoglycaemia, with ORs suggesting that patients with a medium BeAM value were more likely to achieve these endpoints (OR, 1.842; 95\% CI, 1.071-3.170; and OR, 1.845; 95\% CI, 1.081-3.148; Table 4). The BeAM value appeared not to be an indicator for the achievement of endpoints that included no weight gain.

\section{Discussion}

BOT-treated patients who had undergone basal insulin optimisation were assigned a BeAM value calculated from two self-measured blood glucose readings, one at bedtime and the other prior to breakfast the next day. The role of a negative BeAM value has been discussed extensively and, in these patients, supplementation of BOT with prandial insulin is not beneficial. Patients with negative BeAM values are typically younger, had a shorter duration of diabetes and lower $\mathrm{HbAlc}$ levels. ${ }^{17} \mathrm{~A}$ high BeAM value is indicative of a large bedtime blood glucose level caused by postprandial hyperglycaemia accumulating during the day. It is a sign that while the administered basal insulin is sufficient for maintaining FBG levels, diabetes has progressed to an extent that PPG cannot be controlled via this treatment alone. The addition of an injection of prandial insulin prior to meals provides an insulin release profile that is relatively physiological. ${ }^{18}$ Furthermore,

Table 2 Change in Blood Glucose Related Characteristics During the Study Period

\begin{tabular}{|c|c|c|c|c|c|c|c|c|}
\hline & \multicolumn{4}{|c|}{ High BeAM Value $(n=182)$} & \multicolumn{4}{|c|}{ Medium BeAM Value $(n=145)$} \\
\hline & Baseline & Endpoint & $\Delta$ & p-value & Baseline & Endpoint & $\Delta$ & p-value \\
\hline Weight (kg) & $87.7 \pm 17.0$ & $88.6 \pm 17.1$ & +0.9 & $<0.0001$ & $92.8 \pm 16.9$ & $93.3 \pm 16.8$ & +0.5 & 0.045 \\
\hline BMI $\left(\mathrm{kg} / \mathrm{m}^{2}\right)$ & $30.7 \pm 5.1$ & $31.1 \pm 5.1$ & +0.4 & $<0.0001$ & $32.3 \pm 5.2$ & $32.5 \pm 5.1$ & +0.2 & 0.0427 \\
\hline $\mathrm{HbAlc}$ level (\%) $[\mathrm{mmol} / \mathrm{mol}]$ & $7.5 \pm 0.7[59 \pm 7]$ & $7.2 \pm 0.8[55 \pm 9]$ & -0.3 & $<0.0001$ & $7.3 \pm 0.7[56 \pm 8]$ & $6.9 \pm 0.8[52 \pm 9]$ & -0.4 & $<0.0001$ \\
\hline FBG (mg/dl) & $105.6 \pm 16.0$ & $114.3 \pm 25.6$ & +8.7 & $<0.0001$ & $107.7 \pm 15.4$ & $114.9 \pm 25.2$ & +7.2 & 0.0031 \\
\hline PPG (mg/dl) & $201.8 \pm 47.9$ & $\mid 43.1 \pm 40.6$ & +58.7 & $<0.0001$ & $172.9 \pm 33.2$ & $133.6 \pm 30.6$ & -39.3 & $<0.0001$ \\
\hline Insulin glargine dose (units) & $37.8 \pm 25.8$ & $44.7 \pm 31.8$ & +6.9 & $<0.0001$ & $35.7 \pm 17.3$ & $42.2 \pm 21.1$ & +6.5 & $<0.0001$ \\
\hline Insulin glulisine dose (units) & $5.1 \pm 1.8$ & $12.3 \pm 6.7$ & +7.3 & $<0.000$ I & $4.9 \pm 2.4$ & $11.2 \pm 6.5$ & +6.3 & $<0.0001$ \\
\hline
\end{tabular}

Notes: Data are given as mean $\pm \mathrm{SD}$. High BeAM value is $>50 \mathrm{mg} / \mathrm{dl}$; medium BeAM value is $0-50 \mathrm{mg} / \mathrm{dl}$.

Abbreviations: BMI, body mass index; HbAlc, glycated haemoglobin; FBG, fasting blood glucose; PPG, postprandial glucose; SD, standard deviation. 
Table 3 Incidence of Hypoglycaemia ${ }^{a}$ and Frequency of Composite Endpoints Achievement

\begin{tabular}{|c|c|c|c|}
\hline & $\begin{array}{l}\text { High BeAM Value } \\
\qquad(\mathrm{n}=182)\end{array}$ & $\begin{array}{l}\text { Medium BeAM Value } \\
\qquad(\mathrm{n}=145)\end{array}$ & p-value \\
\hline Confirmed symptomatic hypoglycaemia ${ }^{b}$ & $5.2 \pm 11.8$ & $2.8 \pm 6.3$ & 0.010 \\
\hline Nocturnal hypoglycaemia & $1.0 \pm 3.1$ & $0.3 \pm 0.9$ & 0.002 \\
\hline Confirmed severe hypoglycaemia $^{c}$ & $0.03 \pm 0.3$ & $0.0 \pm 0.2$ & 0.149 \\
\hline $\mathrm{HbAlc}<7 \%[53 \mathrm{mmol} / \mathrm{mol}]$ & 39.0 & 62.8 & $<0.0001$ \\
\hline $\mathrm{HbAlc}<7 \%$ [53 mmol/mol] and no confirmed symptomatic hypoglycaemia ${ }^{\mathrm{b}}$ & 23.6 & 40.7 & 0.0005 \\
\hline $\mathrm{HbAlc}<7 \%[53 \mathrm{mmol} / \mathrm{mol}]$ and no confirmed severe hypoglycaemia ${ }^{c}$ & 38.5 & 62.1 & $<0.0001$ \\
\hline $\mathrm{HbAlc}<7 \%[53 \mathrm{mmol} / \mathrm{mol}]$ and no weight gain & 19.8 & 30.3 & 0.0145 \\
\hline $\begin{array}{l}\mathrm{HbAlc}<7 \%[53 \mathrm{mmol} / \mathrm{mol}] \text { and no confirmed symptomatic hypoglycaemia } \\
\text { and no weight gain }\end{array}$ & 12.1 & 20.7 & 0.0177 \\
\hline $\begin{array}{l}\mathrm{HbAlc}<7 \%[53 \mathrm{mmol} / \mathrm{mol}] \text { and no confirmed severe hypoglycaemia and no } \\
\text { weight gain }{ }^{\mathrm{c}}\end{array}$ & 19.2 & 30.3 & 0.0102 \\
\hline
\end{tabular}

Notes: Data are given as mean \pm SD or \% of patients achieving endpoint. High BeAM value is $>50 \mathrm{mg} / \mathrm{d}$; medium BeAM value is $0-50 \mathrm{mg} / \mathrm{dl}$. ${ }^{a}$ Events per patient-year. bSymptomatic hypoglycaemia is defined as blood glucose $<60 \mathrm{mg} / \mathrm{dl}$. 'Severe hypoglycaemia is defined as blood glucose $\leq 36 \mathrm{mg} / \mathrm{dl}$.

Table 4 Endpoint Predictors for Medium vs High BeAM Value Groups

\begin{tabular}{|c|c|c|c|}
\hline & $\begin{array}{l}\text { Odds } \\
\text { Ratio }\end{array}$ & $\begin{array}{c}\text { (Wald 95\% Confidence } \\
\text { Limits) }\end{array}$ & p-value \\
\hline Confirmed symptomatic hypoglycaemia ${ }^{\mathrm{a}}$ & 0.702 & $(0.425-1.160)$ & 0.167 \\
\hline Nocturnal hypoglycaemia & 0.674 & $(0.322-1.4 I I)$ & 0.342 \\
\hline Confirmed severe hypoglycaemia ${ }^{b}$ & 0.514 & $(0.050-5.326)$ & 0.577 \\
\hline $\mathrm{HbAlc}<7 \%[53 \mathrm{mmol} / \mathrm{mol}]$ & 1.842 & $(1.07 I-3.170)$ & 0.027 \\
\hline $\mathrm{HbAlc}<7 \%[53 \mathrm{mmol} / \mathrm{mol}]$ and no confirmed symptomatic hypoglycaemia ${ }^{a}$ & 1.845 & $(1.081-3.148)$ & 0.025 \\
\hline $\mathrm{HbAlc}<7 \%[53 \mathrm{mmol} / \mathrm{mol}]$ and no weight gain & 1.104 & $(0.613-1.987)$ & 0.742 \\
\hline $\begin{array}{l}\text { HbAlc }<7 \%[53 \mathrm{mmol} / \mathrm{mol}] \text { and no confirmed symptomatic hypoglycaemia and no } \\
\text { weight gain }^{\text {a }}\end{array}$ & 1.156 & $(0.64 I-2.083)$ & 0.630 \\
\hline
\end{tabular}

Notes: a'Symptomatic hypoglycaemia is defined as blood glucose $<60 \mathrm{mg} / \mathrm{dl}$. ${ }^{b}$ Severe hypoglycaemia is defined as blood glucose $\leq 36 \mathrm{mg} / \mathrm{dl}$.

as the greatest contribution to daytime hyperglycaemia is usually the largest meal, the addition of a single injection of prandial insulin prior to the meal with the highest glycaemic impact is often sufficient to achieve adequate blood glucose control. ${ }^{13,14,19}$ With this in mind, we would suggest a stepwise increase in the utility of the BeAM from low (no indication for insulin glulisine), to medium (insulin glulisine may or may not be a reasonable addition) to high (insulin glulisine is a good treatment strategy).

One of the biggest challenges with studies such as this is determining which is the patient's largest/main meal - is it breakfast, lunch or evening meal? Even in the two studies used in this analysis, there were variations in the largest meal. In the POC study, the main meal was breakfast for 10 patients, lunch for 14 patients and dinner for 25 patients. ${ }^{14}$ Conversely, in the OPAL trial, 162 patients received their insulin glulisine at breakfast (Group 1), and 154 at the main meal (Group 2). ${ }^{13}$ In an ideal scenario, patients would consume their main meal at the same time of day to allow for a more standardised treatment approach, but this is unrealistic. The data provided in this study, however, provide information on the effectiveness of a single daily injection of insulin glulisine after the main meal, irrespective of its timing. 
At baseline in the two trials that provided the data for the BeAM study, patients were initiated on the basal-plus strategy using insulin glulisine. For the present analysis, information acquired over a 3- to 6-month observation period was collected for patients with a retrospectively calculated high or medium BeAM value. Patients with high BeAM values were slightly older and had longer diabetes duration, which is consistent with their disease having progressed further than that of the medium BeAM patients. Accordingly, their PPG levels were higher, demonstrating that the basal insulin was not as effective in controlling glucose levels after meals. As expected, PPG levels decreased greatly as a result of the addition of the prandial insulin to the BOT. Though this trend was evident for both groups, a greater reduction was observed in patients in the high BeAM group compared to those in the medium group; demonstrating the particular efficacy of the basal plus approach for the former patients.

HbAlc levels were reduced in both the high and medium BeAM value groups, with no apparent difference between groups in terms of magnitude. A higher proportion of patients with a medium BeAM value achieved an HbA1c level below $7 \%[53 \mathrm{mmol} / \mathrm{mol}]$ at the end of the observation periods, which is unsurprising considering that patients of this group were closer to the target value when $\mathrm{HbA1c}$ levels were documented at baseline. On the other hand, mean FBG levels increased slightly for both groups, with a statistically significant rise for patients with a high BeAM value. This may be due to sub-optimal insulin glargine dosages due to more moderate titration of the drug after the addition of insulin glulisine to the treatment regimen. Indeed, increases in insulin glargine dosage during the observation periods were fairly low. This indicates that while the supplementation of BOT with prandial insulin is efficient for reducing PPG and HbAlc levels, further increases in basal insulin should not be overlooked.

Over the course of the study, the insulin glargine dose increased in patients with both a high BeAM value $(+6.9$ units) and a medium BeAM value (+6.5 units). Absolute doses were slightly higher in patients with a high BeAM at both baseline and the follow-up. Increasing the basal insulin dose contributes to improving the general glucose control, such as the HbAlc. Furthermore, the BeAM value focuses on patients that may have appropriate $\mathrm{HbA} 1 \mathrm{c}$ values but still experience postprandial hyperglycaemia. As insulin glargine doses were increased to a similar extent in both groups, a bias arising from this for the interpretation of the BeAM value is not expected.
Hypoglycaemic events were slightly more common in the high BeAM group than in the medium group during the study periods. However, less than $2 \%$ of patients experienced a severe episode. This indicates that the addition of the prandial insulin to the BOT was relatively safe, with rates of symptomatic hypoglycaemia similar to those reported for patients receiving BOT in other studies. ${ }^{20-23}$ While decreases in HbAlc levels were found for both BeAM groups over time, a higher proportion of medium BeAM patients achieved the target HbA1c endpoint $(<7 \%$ [53 mmol/mol]). Concurrently, multivariate analysis showed a high BeAM value to be associated with a lower probability of patients achieving this endpoint. Similarly, meeting the composite endpoint of $\mathrm{HbA1c}$ $<7 \%$ [53 mmol/mol] and no hypoglycaemia was also found to be less likely for patients with a high BeAM value. The achievement of composite endpoints which included no weight gain as a criterion differed less between the two groups, though the achievement rate was again higher in the patients with a medium BeAM value.

There are a number of limitations to the present study. Firstly, as the data were pooled from two independent trials, there are significant differences in the protocols. The most notable of these is that only the POC trial included a run-in period where the basal insulin was optimised. ${ }^{14}$ Furthermore, the period between baseline and endpoint was a lot shorter in the POC trial (3 months in comparison to 6 months for the OPAL trial). ${ }^{13,14}$ These relatively short data collection periods raise the question of whether the dosages of insulin glargine and insulin glulisine were fully optimised by study completion, and whether the maximal therapeutic effects had been achieved at this point. A longer observation period may have demonstrated more significant differences in blood glucose level changes and rates of hypoglycaemia, and future studies should be carried out to investigate this hypothesis. Ideally, this study would have used a control group. Unfortunately, however, there was only a small number of patients in the POC study who did not receive glulisine, which leaves insufficient numbers of patients for reasonable analyses in comparison to the other groups. Although BeAM provides valuable data for this study, continuous glucose monitoring would be the ideal modality to assess the effect of adding insulin glulisine. Finally, the retrospective nature of this study is a limitation but is sufficient for the proof-of-concept study presented here. Prospective 
determination of the BeAM value and its consideration for treatment warrant further investigation.

\section{Conclusions}

The data indicate that insulin glulisine supplementation of BOT is safe and effective for lowering HbAlc and PPG levels in patients with a high BeAM value. However, patients with a medium value also responded well to the treatment change, with a significantly higher proportion achieving the composite endpoints described here. This suggests that the addition of prandial insulin to BOT should be considered not only for patients with a high BeAM value but also for those with a more moderate value. The BeAM value is an easy-to-determine marker for the utility of short-acting insulin and, therefore, should be determined in all patients. Furthermore, the data demonstrate the importance of continual optimisation of basal insulin after the addition of prandial insulin supplementation.

\section{Acknowledgments}

The reported analysis was funded by Sanofi and carried out by Novosys Health. The editorial support provided by IPPMed, Cloppenburg, Germany was funded by Sanofi and is acknowledged. The data have been presented in parts as a poster presentation at:

1. Austrian Society of Diabetes Congress 2015 (43. Jahrestagung der Österreichischen Diabetes Gesellschaft); Wiener Klinische Wochenschrift 2015: $127 ; 131-162$

https://link.springer.com/article/10.1007/s00508015-0883-7

2. Germany Society of Diabetes Congress 2015 (P302); Diabetologie und Stoffwechsel 2015; 10-P302

https://www.thieme-connect.de/products/ejournals/ abstract/10.1055/s-0035-1549808

3. American Diabetes Associations 2015 (Poster 1036-P) https://diabetes.diabetesjournals.org/content/dia betes/64/Supplement_1/A235.full.pdf

\section{Author Contributions}

All authors made substantial contributions to conception and design, acquisition of data, or analysis and interpretation of data; took part in drafting the article or revising it critically for important intellectual content; agreed to submit to the current journal; gave final approval of the version to be published; and agree to be accountable for all aspects of the work.

\section{Disclosure}

Stephan Kress (SK), Ariel Zisman (AZ), Peter Bramlage (PB) and Thorsten Siegmund (TS) declare to have received research funding and/or consultancy fees from Sanofi. TS is the part of the speaker bureau for Abbott, Ascensia, Astra Zeneca, Boehringer Ingelheim, Dexcom, Eli Lilly, Medtronic, Roche, Novo Nordisk, Sanofi, and MSD; advisory board for Abbott, Ascensia, Astra Zeneca, Boehringer Ingelheim, Eli Lilly, Medtronic, Roche, Novo Nordisk, Sanofi, outside the submitted work. Anja Borck (AB) is an employee of Sanofi. The authors report no other conflicts of interest in this work.

\section{References}

1. U.K. prospective diabetes study 16 . Overview of 6 years' therapy of type II diabetes: a progressive disease. U.K. Prospective Diabetes Study Group. Diabetes. 1995;44(11):1249-1258. doi:10.2337/diab. 44.11.1249

2. Davies MJ, D'Alessio DA, Fradkin J, et al. Management of hyperglycemia in type 2 diabetes, 2018. A consensus report by the American Diabetes Association (ADA) and the European Association for the Study of Diabetes (EASD). Diabetes Care. 2018;41(12):2669-2701. doi:10.2337/dci18-0033

3. Turner RC, Cull CA, Frighi V, Holman RR. Glycemic control with diet, sulfonylurea, metformin, or insulin in patients with type 2 diabetes mellitus: progressive requirement for multiple therapies (UKPDS 49). UK Prospective Diabetes Study (UKPDS) Group. JAMA. 1999;281(21):2005-2012. doi:10.1001/jama.281.21.2005

4. Bonora E, Corrao G, Bagnardi V, et al. Prevalence and correlates of post-prandial hyperglycaemia in a large sample of patients with type 2 diabetes mellitus. Diabetologia. 2006;49(5):846-854. doi:10.1007/ s00125-006-0203-x

5. Raccah D, Bretzel RG, Owens D, Riddle M. When basal insulin therapy in type 2 diabetes mellitus is not enough-what next? Diabetes Metab Res Rev. 2007;23(4):257-264. doi:10.1002/dmrr.733

6. Riddle M, Umpierrez G, DiGenio A, Zhou R, Rosenstock J. Contributions of basal and postprandial hyperglycemia over a wide range of A1C levels before and after treatment intensification in type 2 diabetes. Diabetes Care. 2011;34(12):2508-2514. doi:10.2337/ dc11-0632

7. Ceriello A, Davidson J, Hanefeld M, et al. Postprandial hyperglycaemia and cardiovascular complications of diabetes: an update. Nutr Metabo Cardiovasc Dis. 2006;16(7):453-456. doi:10.1016/j.numecd. 2006.05.006

8. Brindisi MC, Rabasa-Lhoret R, Chiasson JL. Postprandial hyperglycaemia: to treat or not to treat? Diabetes Metab. 2006;32(2):105-111. doi:10.1016/S1262-3636(07)70256-2

9. Cavalot F, Pagliarino A, Valle M, et al. Postprandial blood glucose predicts cardiovascular events and all-cause mortality in type 2 diabetes in a 14-year follow-up: lessons from the San Luigi Gonzaga Diabetes Study. Diabetes Care. 2011;34(10):2237-2243. doi:10.23 37/dc10-2414

10. Home PD. The pharmacokinetics and pharmacodynamics of rapid-acting insulin analogues and their clinical consequences. Diabetes Obes Metab. 2012;14(9):780-788. doi:10.1111/j.14631326.2012.01580.x 
11. Leahy JL. Basal-prandial insulin therapy: scientific concept review and application. Am J Med Sci. 2006;332(1):24-31. doi:10.1097/ 00000441-200607000-00005

12. Del Prato S, Nicolucci A, Lovagnini-Scher AC, Turco S, Leotta S, Vespasiani G. Telecare Provides comparable efficacy to conventional self-monitored blood glucose in patients with type 2 diabetes titrating one injection of insulin glulisine-the ELEONOR study. Diabetes Technol Ther. 2012;14(2):175-182. doi:10.1089/ dia.2011.0163

13. Lankisch MR, Ferlinz KC, Leahy JL, Scherbaum WA. Introducing a simplified approach to insulin therapy in type 2 diabetes: a comparison of two single-dose regimens of insulin glulisine plus insulin glargine and oral antidiabetic drugs. Diabetes Obes Metab. 2008;10(12):1178-1185.

14. Owens DR, Luzio SD, Sert-Langeron C, Riddle MC. Effects of initiation and titration of a single pre-prandial dose of insulin glulisine while continuing titrated insulin glargine in type 2 diabetes: a 6-month 'proof-of-concept' study. Diabetes Obes Metab. 2011;13(11):1020-1027. doi:10.1111/j.1463-1326.2011.01 459.x

15. Vora J, Cohen N, Evans M, Hockey A, Speight J, Whately-Smith C. Intensifying insulin regimen after basal insulin optimization in adults with type 2 diabetes: a 24-week, randomized, open-label trial comparing insulin glargine plus insulin glulisine with biphasic insulin aspart (LanScape). Diabetes Obes Metab. 2015;17(12):1133-1141. doi:10.1111/dom. 12528

16. Zisman A, Morales F, Stewart J, Stuhr A, Vlajnic A, Zhou R. BeAM value: an indicator of the need to initiate and intensify prandial therapy in patients with type 2 diabetes mellitus receiving basal insulin. BMJ Open Diabetes Res Care. 2016;4(1):e000171. doi:10. 1136/bmjdrc-2015-000171
17. Siegmund T, Borck A, Zisman A, Bramlage P, Kress S. A higher blood glucose level pre-breakfast in comparison to bedtime is a contraindication for intensification of prandial insulin therapy in patients with type 2 diabetes - The impact of a negative BeAM value. J Clin Transl Endocrinol. 2018;14:34-38. doi:10.1016/j.jcte.2018. 10.002

18. Pearson J, Powers MA. Systematically initiating insulin: the staged diabetes management approach. Diabetes Educ. 2006;32(1 Suppl): 19S-28S. doi:10.1177/0145721705285640

19. Owens DR. Stepwise intensification of insulin therapy in type 2 diabetes management-exploring the concept of the basal-plus approach in clinical practice. Diabetic Med. 2013;30(3):276-288. doi:10.1111/dme.12019

20. Bretzel RG, Eckhard M, Landgraf W, Owens DR, Linn T. Initiating insulin therapy in type 2 diabetic patients failing on oral hypoglycemic agents: basal or prandial insulin? The APOLLO trial and beyond. Diabetes Care. 2009;32(Suppl 2):S260-S265. doi:10.2337/dc09-S319

21. Yki-Jarvinen H, Kauppinen-Makelin R, Tiikkainen M, et al. Insulin glargine or NPH combined with metformin in type 2 diabetes: the LANMET study. Diabetologia. 2006;49(3):442-451. doi:10.1007/ s00125-005-0132-0

22. Eliaschewitz FG, Calvo C, Valbuena H, et al. Therapy in type 2 diabetes: insulin glargine vs. NPH insulin both in combination with glimepiride. Arch Med Res. 2006;37(4):495-501. doi:10.1016/j. arcmed.2005.10.015

23. Odawara M, Kadowaki T, Naito Y. Incidence and predictors of hypoglycemia in Japanese patients with type 2 diabetes treated by insulin glargine and oral antidiabetic drugs in real-life: ALOHA post-marketing surveillance study sub-analysis. Diabetol Metab Syndr. 2014;6(1):20. doi:10.1186/1758-5996-6-20

\section{Publish your work in this journal}

Diabetes, Metabolic Syndrome and Obesity: Targets and Therapy is an international, peer-reviewed open-access journal committed to the rapid publication of the latest laboratory and clinical findings in the fields of diabetes, metabolic syndrome and obesity research. Original research, review, case reports, hypothesis formation, expert opinion and commentaries are all considered for publication. The manuscript management system is completely online and includes a very quick and fair peer-review system, which is all easy to use. Visit http://www.dovepress.com/testimonials.php to read real quotes from published authors. 